\title{
Cognitive subtypes of dyslexia are characterized by distinct patterns of grey matter volume
}

\author{
Katarzyna Jednoróg • Natalia Gawron • \\ Artur Marchewka $\cdot$ Stefan Heim • Anna Grabowska
}

Received: 10 October 2012/ Accepted: 5 June 2013/Published online: 18 June 2013

(C) The Author(s) 2013. This article is published with open access at Springerlink.com

\begin{abstract}
The variety of different causal theories together with inconsistencies about the anatomical brain markers emphasize the heterogeneity of developmental dyslexia. Attempts were made to test on a behavioral level the existence of subtypes of dyslexia showing distinguishable cognitive deficits. Importantly, no research was directly devoted to the investigation of structural brain correlates of these subtypes. Here, for the first time, we applied voxelbased morphometry (VBM) to study grey matter volume (GMV) differences in a relatively large sample $(n=46)$ of dyslexic children split into three subtypes based on the cognitive deficits: phonological, rapid naming, magnocellular/dorsal, and auditory attention shifting. VBM revealed GMV clusters specific for each studied group including areas of left inferior frontal gyrus, cerebellum, right putamen, and bilateral parietal cortex. In addition, using
\end{abstract}

Electronic supplementary material The online version of this article (doi:10.1007/s00429-013-0595-6) contains supplementary material, which is available to authorized users.

K. Jednoróg $(\bowtie) \cdot$ A. Grabowska

Laboratory of Psychophysiology, Department of

Neurophysiology, Nencki Institute of Experimental Biology,

Pasteur 3, 02-093 Warsaw, Poland

e-mail: k.jednorog@nencki.gov.pl

N. Gawron

Faculty of Psychology, University of Warsaw, Warsaw, Poland

\section{A. Marchewka}

Laboratory of Brain Imaging, Neurobiology Centre, Nencki

Institute of Experimental Biology, Warsaw, Poland

\section{S. Heim}

Section Structural-Functional Brain Mapping, Department of Psychiatry, Psychotherapy and Psychosomatics, Medical School, RWTH Aachen University, Aachen, Germany discriminant analysis on these clusters $79 \%$ of cross-validated cases were correctly re-classified into four groups (controls vs. three subtypes). Current results indicate that dyslexia may result from distinct cognitive impairments characterized by distinguishable anatomical markers.

Keywords VBM - Dyslexia - Cognitive deficits . Heterogeneity

\section{Introduction}

Developmental dyslexia is defined as a specific deficit in reading acquisition that cannot be accounted for by low intelligence, poor educational opportunities, or any obvious sensory or neurological damage. Numerous theories were proposed trying to identify potential causes of dyslexia, however, no consensus was reached yet with regard to the neurological and cognitive basis of the disorder. It can be partly explained by the fact that the large body of data on

S. Heim

JARA-Translational Brain Medicine, Jülich and Aachen,

Germany

S. Heim

Section Neurological Cognition Research, Department of Neurology, Medical School, RWTH Aachen University, Aachen, Germany

S. Heim

Research Centre Jülich, Institute of Neuroscience and Medicine (INM-1), Jülich, Germany

A. Grabowska

University of Social Sciences and Humanities, Warsaw, Poland 
cognitive deficits in dyslexia fails to fit into a single coherent theoretical framework and partly by the fact that the disorder is heterogeneous (Ramus and Ahissar 2012).

There is great variability in how dyslexia can be expressed in an individual relative to another depending on particular cognitive deficits that are present or not. Attempts were made to find distinguishable subtypes of the disorder. Several studies examined different dyslexia theories in multiple case studies of either adults (Ramus et al. 2003) or children (White et al. 2006) trying to assess the prevalence of each of the studied cognitive deficit adopting a criterion of deviance $=1.65 \mathrm{SD}$. In both aforementioned studies, performed on British native speakers, the phonological deficit was the most common, while the sensory deficits (magnocellular, auditory, motor/cerebellar) were less represented. Another study using a different criterion for deviance (below the 10th percentile) tried to determine if a proportion of dyslexic children could be characterized as suffering mainly from a selective visual span deficit or a phonological impairment (Bosse et al. 2007). The research showed that both French and British dyslexic children could be divided into four subgroups-having selective phonological, selective visual span deficit, both or none. Finally, using cluster analysis, Heim et al. (2008) divided German dyslexic children into three clusters with different cognitive deficits. Specifically, cluster no. 1 compared to age-matched controls had worse phonological awareness, cluster no. 2 had an attention deficit, whereas cluster no. 3 performed worse on phonological, auditory, and magnocellular tasks.

These studies show that distinguishable phenotypes of dyslexia exist on the cognitive level. There is, however, much more limited understanding of the potential neural markers of these specific subtypes. At the neurofunctional level, first attempts were made to relate cognitive profiles of dyslexia to brain activation during reading (Heim et al. 2010b), phonological awareness, visual-spatial attention, visual processing, and auditory processing (Heim et al. 2010a; for a review see Heim and Grande 2012). However, we are not aware of any study successfully defining subtypes of dyslexia and providing evidence for distinct cognitive and neuroanatomical profiles associated with each subtype.

Previous voxel-based morphometry (VBM) studies revealed differences in brain structure between children and adults with developmental dyslexia and controls. When summarized in a review (Richardson and Price 2009), increases and decreases of grey matter volume (GMV) in group comparisons of developmental dyslexics and good readers, constitute a widely distributed set of regions in both left and right hemispheres. The most frequently reported areas include: posterior temporal/temporo-parietal regions with increases and decreases of GMV (Brambati et al. 2004; Hoeft et al. 2007; Silani et al. 2005; Steinbrink et al. 2008), decreases of GMV in the left inferior frontal
(Brown et al. 2001; Eckert et al. 2005), decreases of GMV in the occipito-temporal regions bilaterally (Eckert et al. 2005; Brambati et al. 2004; Kronbichler et al. 2008), and decreases of GMV in the cerebellum bilaterally (Brown et al. 2001; Brambati et al. 2004; Eckert et al. 2005; Kronbichler et al. 2008). Finally, there are also studies where no differences in GMV between dyslexic and control groups were revealed (Pernet et al. 2009). Taking into account the heterogeneity of behavioral deficits, it is not surprising that VBM studies of dyslexia do not always agree one with the other, depending on the sample at hand, its age and the behavioral profile.

Here, we aimed at distinguishing specific dyslexic subtypes based on examining four cognitive domains: phonological awareness, rapid automatized naming, visual magnocellular-dorsal processing, and auditory attention shifting. We hypothesize that dyslexic subtypes can be characterized by a specific pattern of GMV.

\section{Method}

Subjects

Eighty-one Polish native speakers took part in the study: 46 dyslexic children $($ mean $=123.1$ months, $\mathrm{SD}=10.6,20$ girls) and 35 control children (mean $=124$ months, $\mathrm{SD}=10.6,22$ girls). They had normal IQ $(>85)$, were born at term ( $>37$ weeks), were right-handed, attended school regularly, and none of them had any history of neurological illness or brain damage and no symptoms of ADHD. The groups were also matched for parental socioeconomic status (SES). Dyslexic children were recruited from education authorities and dyslexia centers and most of them had received some degree of remedial instruction in reading, spelling or oral language. The study was approved by the Warsaw Medical University Ethical Committee and all children and their parents gave written informed consent to the study.

\section{Procedure}

Testing was performed in three successive phases: (i) behavioral tests of reading and writing, (ii) Wechsler intelligence subtests (WISC-R) and other cognitive functions described in details below, and (iii) an MRI scan.

Behavioral tests

Reading tests

Reading ability was assessed using real word reading (WDREAD) from the normalized Polish battery of tests 
used for diagnosis of dyslexia (Bogdanowicz et al. 2008). Participants had to read aloud single words as quickly and accurately as possible. A measure of correctly read words per second was used. The majority of dyslexic children had independently received a diagnosis of developmental dyslexia. Non-word reading (NWREAD) was taken from the same battery. Children had to read aloud pseudowords as quickly and accurately as possible and a measure of correctly read pseudowords per second was used. Spelling was measured as percent of correctly typed words from a dictation of text.

\section{Phonological awareness}

Phonological awareness was assessed using phoneme deletion task (PHONDEL) (Bogdanowicz et al. 2008). In each item, a child has to delete a given phoneme from the spoken word, either at the beginning, in the middle or at the end of the word. The percent of accurately produced items was recorded.

\section{Rapid automatized naming}

Rapid automatized naming (RAN) was assessed using two non-alphabetic subtests of a Polish version of the test, i.e., objects and colors. A standardized score for time needed for naming both objects and colors was used.

\section{Magnocellular-dorsal functions}

Coherence motion thresholds (CMT) were measured using a random dot kinematogram consisting of a patch of 300 white dots $\left(0.05^{\circ}\right)$ that were randomly distributed within a $12^{\circ} \times 12^{\circ}$ square on a black background (viewing distance $57 \mathrm{~cm}$ ) on a $15.5^{\prime \prime}$ screen. A variable proportion of these dots moved coherently, at a velocity of $15 \%$, either upwards or downwards amongst the remaining randomly moving dots (Brownian motion). Stimuli were presented for $3 \mathrm{~s}$, with each animation frame lasting $25 \mathrm{~ms}$. The dots had a lifetime of $150 \mathrm{~ms}$ after which they reappeared in a random position. Subjects reported the direction of perceived coherent motion by pressing an appropriate mouse key. The threshold was determined by a $3 \mathrm{~dB}$-up, $1 \mathrm{~dB}$-down, two alternative forced-choice staircase procedure. Threshold was computed by taking the geometric average of the last 8 of 10 reversal points. Each series was repeated three times and the mean of two best series comprised individual's overall motion coherence threshold (Talcott et al. 2000).

\section{Auditory attention shifting}

Auditory stream segregation threshold (SST) was employed following the Lallier et al. (2009) study. The auditory sequences were composed of high $(1,000 \mathrm{~Hz})$ and low $(400 \mathrm{~Hz})$ pitch pure tones presented in alternation. Each sequence lasted $5 \mathrm{~s}$. Tones lasted $40 \mathrm{~ms}$ (including $5 \mathrm{~ms}$ linear onset/offset amplitude ramps). Stimuli were presented binaurally through headphones (at approximately $65 \mathrm{~dB}$ ). Within each trial, a fixation cross, subtending $0.5^{\circ} \times 0.5^{\circ}$ of visual angle appeared at the center of the screen followed by the auditory sequence after $500 \mathrm{~ms}$. Children reported in a forced-choice paradigm whether they had perceived one stream or two streams. The threshold was determined by a 'one-up, one-down' adaptive two forced-choice method. Each sequence of alternating tones depending on stimulus onset asynchrony (SOA) leads to either a one- (connected) or a twostream (segregated) percept. On the basis of the subject's response, the computer program automatically either shortened the SOA (after 'connected' answer) or lengthened it. The session included 30 sequences and started with a $300 \mathrm{~ms}$ SOA. The SOA was first decreased or increased by steps of $40 \mathrm{~ms}$ and by steps of $20 \mathrm{~ms}$ after the first categorical change, then by steps of $10 \mathrm{~ms}$ after the second categorical change, and, finally, by steps of $5 \mathrm{~ms}$ after the third categorical change. The SST was defined as the mean SOA over the last 10 trials. This measure corresponded to the SOA at which participants could no longer dissociate the one-stream from the two-stream percepts and reflected the highest speed at which participants were able to shift automatically their attentional focus.

\section{Behavioral data analysis}

All analyses were conducted with SPSS 18 (SPSS Inc., Chicago, IL, USA). Following Heim et al. (2008, 2010a), the existence of subtypes within the dyslexic sample was tested using a two-step cluster analysis. A detailed description of the procedure together with the parameters can be found in Heim et al. (2008). Here, the PHONDEL scores, the RAN, the CMT, and the SST were entered as variables of interest. Reading and IQ were not included since they served as diagnostic inclusion criteria. Next, the resulting three clusters were compared to the control group and each other with respect to reading ability and cognitive measures using one-way ANOVA followed by pairwise comparisons with Bonferroni correction applied.

\section{MRI data acquisition}

Imaging data was acquired using 1.5-Tesla MRI scanner (Magnetom Avanto; Siemens, Erlangen, Germany) equipped with 32-channel phased array head coil. Detailed anatomical data of the brain were acquired with sagittal T1-weighted (time repetition $=1,720 \mathrm{~ms}$; time echo $=2.92 \mathrm{~ms}) \quad$ and $\quad \mathrm{T} 2$-weighted $\quad(\mathrm{TR}=3,200 \mathrm{~ms}$; $\mathrm{TE}=381 \mathrm{~ms}$ ) MPRAGE sequences with isotropic voxel size $(1 \times 1 \times 1 \mathrm{~mm})$. 
VBM analyses and statistics

Statistical Parametric Mapping 8 (Wellcome Trust Center for Neuroimaging, London, UK) was used for data processing and statistical analyses. New segment algorithm was applied in order to obtain basic tissue classes (Ashburner and Friston 2005) with pediatric priors created using TemplateO-Matic toolbox (Wilke et al. 2008). Next, a study specific template was obtained using the Diffeomorphic Anatomical Registration Through Exponentiated Lie Algebra (DARTEL) toolbox (Ashburner 2007). Finally, images were spatially normalized to MNI space, modulated and smoothed with 6-mm isotropic Gaussian kernel.

Regional differences in GMV between controls and three dyslexic clusters were calculated using one-way ANOVA with age, sex, SES, and total intracranial volume as nuisance variables. Clusters from whole brain exploratory analysis $(p<0.001)$ were corrected using non-stationary cluster extended correction $(p<0.05)$ as implemented in VBM8 toolbox, which is crucial to adjust cluster sizes according to local roughness (Hayasaka et al. 2004).

In order to characterize GMV for each group, we performed $t$ tests comparing each group against all others. This analysis was meant to reveal the most characteristic GMV features for each group. Then, to dissociate unique and shared GMV effects for different groups we performed additional contrasts using inclusive masking option in SPM. Contrasts to be masked were maintained at $p<0.001$, whereas the inclusive mask was thresholded at $p<0.05$ as implemented in previous studies (Uncapher and Rugg 2009; Joly et al. 2012).

Next, average GMV signal from all the significant clusters in the first analysis was extracted using the MarsBaR toolbox (Brett et al. 2002). Then the GMV of significant clusters was fed as predictor into a discriminant analysis in order to test how well the diagnostic group membership would be predicted by the GMV values. The independent variables (i.e., the GMV values per region) were entered together. The prior probabilities were adapted to the group sizes. The analysis was based on Wilk's lambda. In order to assess the re-classification of the subjects into the diagnostic groups based on their GMV values, we used the leave-one-out classification approach, which is more conservative than the standard version because it eliminates the influence of each classified data-point on the sample to which it is compared.

\section{Results}

Behavioral data

As shown in Table 1, the dyslexic and control children differed significantly in WDREAD and NWREAD,
Table 1 Differences in behavioral measures between control and dyslexic children

\begin{tabular}{lccrl}
\hline Measure & $\begin{array}{l}\text { Control, mean } \\
(\mathrm{SD})\end{array}$ & $\begin{array}{l}\text { Dyslexic, mean } \\
(\mathrm{SD})\end{array}$ & $t$ test & $p$ \\
\hline WDREAD & $1.02(0.35)$ & $0.29(0.19)$ & 10.93 & $<0.001$ \\
NWREAD & $0.55(0.14)$ & $0.32(0.14)$ & 7.06 & $<0.001$ \\
Spelling & $6.89(1.45)$ & $3.21(1.35)$ & 11.74 & $<0.001$ \\
PHONDEL & $95.40(5.05)$ & $83.84(13.68)$ & 5.28 & $<0.001$ \\
RAN & $5.89(1.79)$ & $4.20(2.07)$ & 3.85 & $<0.001$ \\
CMT & $0.21(0.05)$ & $0.23(0.08)$ & -1.01 & $\mathrm{~ns}$ \\
SST & $160.93(50.20)$ & $183.15(59.53)$ & -1.78 & $\mathrm{~ns}$ \\
\hline
\end{tabular}

WDREAD word reading, NWREAD non-word reading, PHONDEL phonological deletion, $R A N$ rapid automatized naming, $C M T$ coherent motion threshold, SST stream segregation threshold

spelling, phonological deletion (PHONDEL), and RAN. However, they did not differ significantly in case of CMT or SST.

\section{Cluster analysis}

The two-step cluster analysis for all four cognitive variables revealed three distinguishable clusters within the dyslexic children (see Fig. 1 for polar plots, bar plots are presented in Fig. S1). Cluster 1 had 14 subjects $(30.4 \%, 5$ girls), cluster 2 had 15 subjects (32.6\%, 9 girls), and cluster 3 had 17 subjects (37\%, 6 girls). Groups did not differ significantly in age or SES.

For all four cognitive variables, the effect of group was significant: $\quad$ PHONDEL-F(3,77) $=25.14 ; \quad p<0.001$; $\mathrm{RAN}-F(3,77)=7.93 ; \quad p<0.001 ; \quad \mathrm{CMT}-F(3,77)=$ $12.01 ; p<0.001 ; \mathrm{SST}-F(3,77)=18.01 ; p<0.001$ (see Table 2). In case of PHONDEL, dyslexic cluster 1 (Dys 1) performed the worse of all groups (for all comparisons $p<0.001$ ), cluster 3 (Dys 3) performed worse than controls $(p=0.015)$, while cluster 2 (Dys 2) did not differ from controls. In RAN, Dys 2 and 3 had lower scores than controls ( $p=0.005$ and $p<0.001$, respectively). In CMT, the highest threshold of all groups had Dys 1 (all $p<0.001$ ), whereas in SST the highest threshold of all groups had Dys 2 (all $p<0.001$ ). All three clusters performed significantly worse than controls on WDREAD, NWREAD, and spelling (all $p<0.001$ ), while there were no differences between the dyslexic clusters.

\section{VBM results}

The dyslexic clusters and control children did not differ significantly in the global brain measures, i.e., total intracranial volume, total grey matter, or white matter volume.

With regard to the local GMV differences, VBM contrasts for controls versus all dyslexic subtypes revealed 

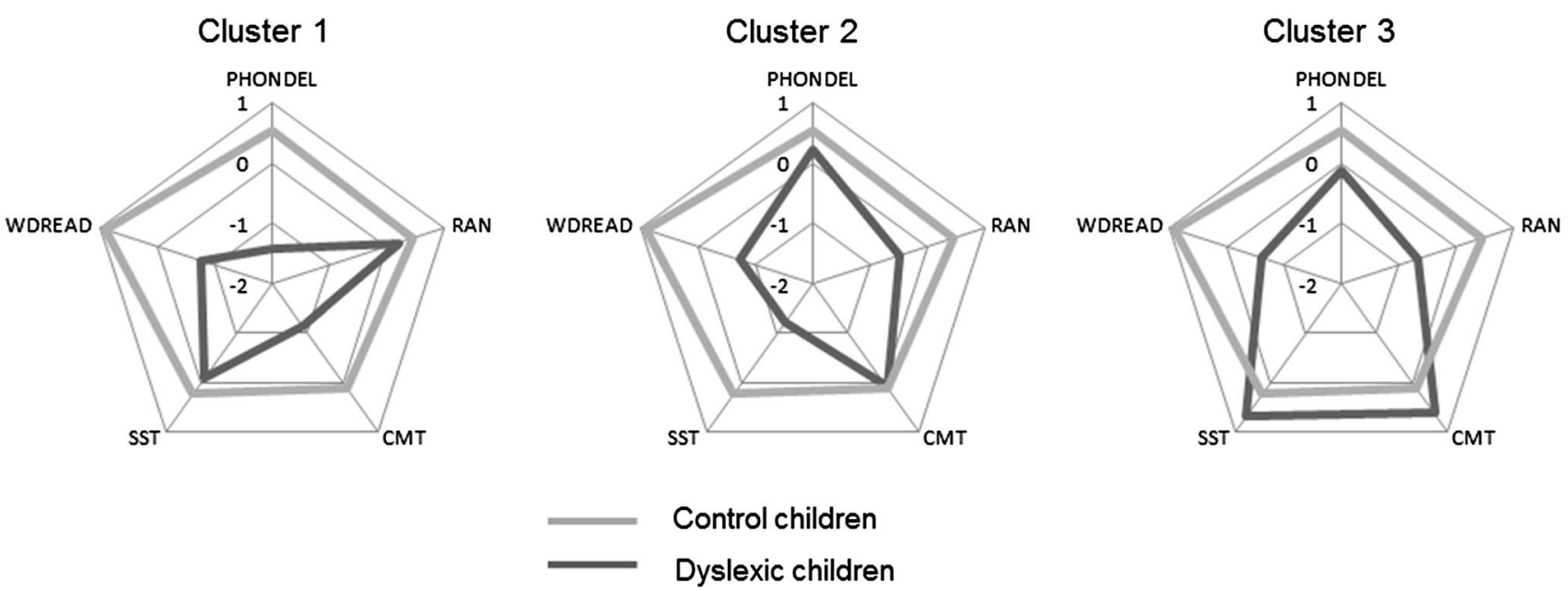

Fig. 1 Comparison of behavioral scores in three clusters of dyslexic children against controls. For the visualization purposes, performance in each test was converted into $z$ scores so that the positive values reflect better performance (for CMT and SST $-z$ is presented)

Table 2 Differences in behavioral measures between control group and dyslexic clusters

\begin{tabular}{|c|c|c|c|c|c|c|c|}
\hline Measure & Controls, mean (SD) & Cluster 1 , mean (SD) & Cluster 2, mean (SD) & Cluster 3, mean (SD) & $F$ & $p$ & Post hoc $p<0.05$ \\
\hline WDREAD & $1.02(0.35)$ & $0.26(0.19)$ & $0.28(0.19)$ & $0.33(0.21)$ & 45.51 & $<0.001$ & $\mathrm{CON}>1,2,3$ \\
\hline NWREAD & $0.55(0.14)$ & $0.33(0.13)$ & $0.30(0.15)$ & $0.34(0.15)$ & 16.67 & $<0.001$ & $\mathrm{CON}>1,2,3$ \\
\hline Spelling & $6.89(1.45)$ & $2.86(0.95)$ & $3.07(1.22)$ & $3.53(1.50)$ & 52.17 & $<0.001$ & $\mathrm{CON}>1,2,3$ \\
\hline PHONDEL & $95.40(5.05)$ & $71.43(15.32)$ & $91.59(7.25)$ & $87.21(9.28)$ & 25.14 & $<0.001$ & $\begin{array}{l}\mathrm{CON}>1,3 \\
2,3, \mathrm{CON}>1\end{array}$ \\
\hline RAN & $5.89(1.79)$ & $5.36(1.78)$ & $3.87(2.2)$ & $3.53(1.87)$ & 7.93 & $<0.001$ & $\mathrm{CON}>2,3$ \\
\hline CMT & $0.21(0.05)$ & $0.30(0.07)$ & $0.21(0.07)$ & $0.17(0.06)$ & 12.01 & $<0.001$ & $1>2,3, \mathrm{CON}$ \\
\hline SST & $160.93(50.20)$ & $178.75(43.47)$ & $243.07(35.97)$ & $133.91(36.62)$ & 18.01 & $<0.001$ & $\begin{array}{l}2>1>3 \\
2>1,3, \mathrm{CON}\end{array}$ \\
\hline
\end{tabular}

WDREAD word reading, NWREAD non-word reading, $P H O N D E L$ phonological deletion, $R A N$ rapid automatized naming, $C M T$ coherent motion threshold, SST stream segregation threshold

significantly reduced GMV for dyslexics compared to controls in the left inferior frontal gyrus (Table 3; Fig. 2). This structure was also revealed when each dyslexic subtype was contrasted to controls (using inclusive masking procedure) showing a common GMV reduction (Table 4). There were no significant differences in GMV for the reverse contrast (dyslexics $>$ controls). When Dys 1 was compared to all other groups, a significant increase in GMV was revealed in the left cerebellum and the right putamen, while a significant reduction was observed in the right dorsal premotor cortex and the left parietal cortex. The increase in the left cerebellum and the right putamen together with a decrease in the right premotor cortex were revealed as unique to the first dyslexic subtype. Dys 2 compared to all other groups was characterized of higher GMV in the left parietal cortex (in a region overlapping with the one showing a decrease in Dys 1 group-see Fig. 3) and medial part of the right superior frontal gyrus, whereas lower GMV was found in left cerebellum (in a region overlapping with the one showing an increase in Dys 1 group). However, no unique effects were found for this subtype using inclusive masking procedure. Finally, Dys 3 compared to all other groups was characterized only by decreased GMV in the right parietal cortex, however, again no unique decreases or increases of GMV for this subtype were revealed. Additionally, there was a common decrease of GMV in the right anterior and middle cingulate gyrus in the first and second dyslexic subtype, whereas a common increase of GMV for the first and third dyslexic subtype was revealed in the left cerebellum.

Next, to test the re-classification of subjects into groups (controls versus three dyslexic subtypes) based on their GMVs, values from structures revealed by VBM analyses were fed into a discriminant analysis. GMV of seven structures (depicted in Table 5) served as independent variables, whereas the dependent variable was group membership. While the first clustering based on behavioral data was performed on dyslexics only, here assignment to 
Table 3 Brain regions with significant grey matter volume difference between the groups

Cluster size indicates number of voxels

$L$ left, $R$ right hemisphere

\begin{tabular}{|c|c|c|c|c|c|}
\hline \multirow[t]{2}{*}{ Brain region } & \multicolumn{3}{|c|}{ MNI coordinates } & \multirow[t]{2}{*}{ T-stat } & \multirow{2}{*}{$\begin{array}{l}\text { Cluster } \\
\text { size }\end{array}$} \\
\hline & $x$ & $y$ & $z$ & & \\
\hline \multicolumn{6}{|l|}{ Controls $>$ all other groups } \\
\hline $\mathrm{L}$ inferior frontal gyrus & -35 & 42 & -21 & 4.42 & 392 \\
\hline All other groups $>$ controls & - & & & & \\
\hline \multicolumn{6}{|l|}{ Dys $1>$ all other groups } \\
\hline L cerebellum, lingual gyrus & -14 & -81 & -18 & 4.97 & 529 \\
\hline $\mathrm{R}$ putamen & 26 & -9 & -15 & 4.33 & 199 \\
\hline \multicolumn{6}{|l|}{ All other groups $>$ Dys 1} \\
\hline $\begin{array}{l}\mathrm{R} \text { dorsal premotor cortex (precentral, middle and } \\
\text { inferior forntal gyri) }\end{array}$ & 54 & 13 & 38 & 5.53 & 221 \\
\hline L parietal cortex (paracentral lobule and postcentral gyrus) & -24 & -35 & 72 & 5.07 & 133 \\
\hline \multicolumn{6}{|l|}{ Dys $2>$ all other groups } \\
\hline L parietal cortex (paracentral lobule and postcentral gyrus) & -26 & -26 & 69 & 6.14 & 352 \\
\hline $\mathrm{R}$ superior medial frontal gyrus & 9 & 49 & 32 & 5.26 & 77 \\
\hline \multicolumn{6}{|l|}{ All other groups $>$ Dys 2} \\
\hline L cerebellum, lingual gyrus & -15 & -77 & -6 & 4.76 & 102 \\
\hline Dys $3>$ all other groups & - & & & & \\
\hline \multicolumn{6}{|l|}{ All other groups $>$ Dys 3} \\
\hline R parietal cortex (supramarginal and postcentral gyri) & 53 & -29 & 50 & 6.11 & 125 \\
\hline
\end{tabular}

one of four groups was possible. In the discriminant analysis, we used leave one out classification where each case in the analysis is classified by the functions derived from all cases other than that case. This analysis revealed three discriminant functions with $79 \%$ of cross-validated grouped cases correctly classified. The accuracies for each group were as following: controls (85.7\%), Dys 1 (85.7 \%), Dys 2 (60\%), Dys 3 (76.5\%).

In addition, a validation of the GMV discriminant scores was accomplished by Pearson correlation analyses between the GMV discriminant scores of three functions and the behavioral variables (Table 5). Significant correlation was noted between the first discriminant function and PHONDEL $(r=0.38, p=0.001)$. The second discriminant function was correlated with the two perceptual thresholds-CMT $(r=0.31, p=0.005)$ and SST $(r=0.33$, $p=0.003)$. Whereas, the third discriminant function was correlated with reading scores-WDREAD $(r=0.40$, $p<0.001)$, NWREAD $(r=0.24, p=0.029)$, spelling $(r=0.40, p<0.001)$, and RAN $(r=0.29, p=0.009)$.

\section{Discussion}

In the present study, we identified three subtypes of dyslexia with distinct cognitive and neurobiological profiles. All had severe reading and spelling impairments compared to controls but did not differ in these measures with each other. On the neuronal level, they showed reduced GMV in the left inferior frontal gyrus relative to age-matched good readers consistent with previous studies (Brown et al. 2001; Eckert et al. 2005; Vinckenbosch et al. 2005). Importantly, this effect was common across all dyslexic subtypes. The left inferior frontal gyrus contributed mostly to the third discriminant function, which was associated with single word and pseudoword reading, spelling, and rapid naming. In line, the activity in this area increased with reading ability and was related to rapid naming (Turkeltaub et al. 2003). It was also shown that the size of inferior frontal gyrus, particularly pars triangularis can predict rapid naming speed in a group of children with predominating double deficit (Eckert et al. 2005).

The first subtype of dyslexic children had worse phonological awareness and magnocellular-dorsal skills compared to all other groups. A similar cluster was previously described by Heim et al. (2008) though in that study children besides phonological and magnocellular had also an auditory deficit. VBM revealed that compared to other groups this subtype was characterized of increased GMV in the left cerebellum, lingual gyrus and right putamen together with a decrease of GMV in the left parietal (mainly somatosensory) and right dorsal premotor cortices. However, only the differences in the left cerebellum, the right putamen and right dorsal premotor cortex were unique for this dyslexic subtype. The second dyslexic subtype had a reverse cognitive profile compared to first subtype, i.e., while phonological and magnocellular-dorsal skills were comparable to controls, the children showed impairments in rapid naming and auditory attention shifting. This was nicely reflected in GMV profiles since in the second 

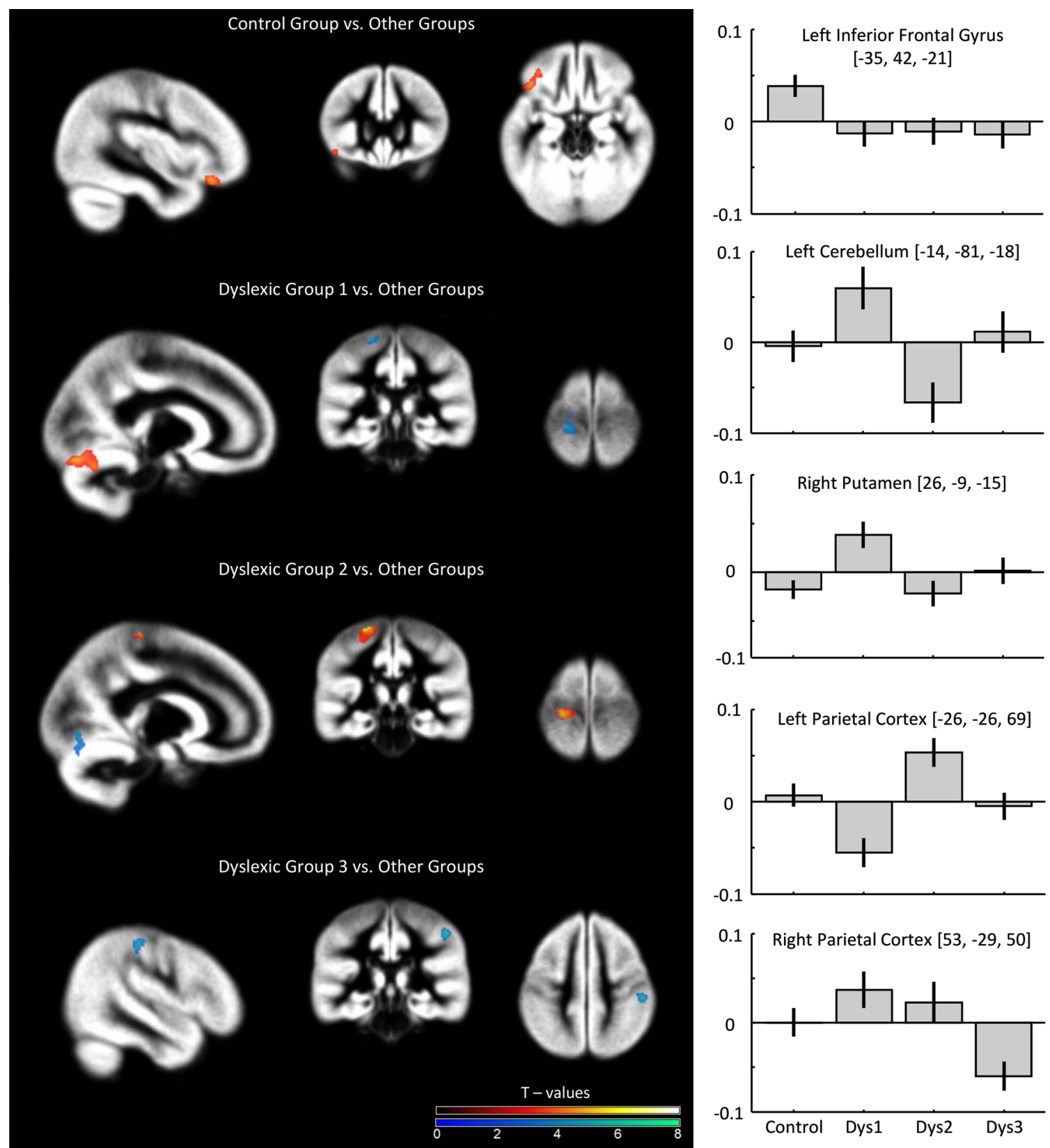

Fig. 2 Grey matter volume differences between the groups (in red decreased GMV; in blue increased GMV) together with contrast estimates for five significant clusters. Results are displayed at uncorrected $p<0.001$

subtype a decrease in GMV in the left cerebellum, lingual gyrus and an increase of GMV in the left parietal (somatosensory) cortex were observed, in regions overlapping with the ones showing a reverse pattern in subtype 1 , together with an increase of GMV in the medial part of the right superior frontal gyrus. However, no unique effects were revealed for this subtype.

The structures differentiating subtypes 1 and 2 contributed to the first discriminant function, which was associated with phonological awareness. Previous anatomical studies yielded inconsistent results for the cerebellum of dyslexic subjects showing either decreased GMV compared to controls (Brown et al. 2001; Brambati et al. 2004; Eckert et al. 2005; Kronbichler et al. 2008) or no differences between the groups followed by a negative association between cerebellar GMV and phonological skills in controls (Kibby et al. 2008; Pernet et al. 2009). Nicolson et al. (2001) have proposed two mechanisms by which cerebellum may play a role in dyslexia. The first is associated with so-called motor-articulatory feedback hypothesis (Heilman et al. 1996), which suggests that recognition of phonemes is dependent on awareness of the positions 
Table 4 Unique and shared grey matter effects for the different groups
Cluster size indicates number of voxels. Contrasts to be masked were maintained at $p<0.001$, whereas the inclusive mask was thresholded at $p<0.05$

$L$ left, $R$ right hemisphere

\begin{tabular}{|c|c|c|c|c|c|c|}
\hline \multirow[t]{2}{*}{ Contrast } & \multirow[t]{2}{*}{ Brain region } & \multicolumn{3}{|l|}{ MNI } & \multirow{2}{*}{$\begin{array}{l}\text { T- } \\
\text { stat }\end{array}$} & \multirow{2}{*}{$\begin{array}{l}\text { Cluster } \\
\text { size }\end{array}$} \\
\hline & & $x$ & $y$ & $z$ & & \\
\hline \multicolumn{7}{|c|}{ Common decreased GMV for each dyslexic group } \\
\hline $\begin{array}{l}\text { Control }>\text { all dys groups masked incl. } \\
(\text { con }>\text { Dys } 1 \& \text { con }>\text { Dys } 2 \& \\
\text { con }>\text { Dys } 3)\end{array}$ & $\mathrm{L}$ inferior frontal gyrus & -35 & 42 & -21 & 4.42 & 276 \\
\hline \multicolumn{7}{|l|}{ Unique decreases in GMV for Dys 1} \\
\hline $\begin{array}{l}\text { Dys } 1<\text { control masked incl. (Dys } \\
1<\text { Dys } 2 \& \text { Dys } 1<\text { Dys } 3 \text { ) }\end{array}$ & $\begin{array}{l}\text { R dorsal premotor } \\
\text { (precentral, middle and } \\
\text { inferior frontal gyri) }\end{array}$ & 55 & 13 & 39 & 5.30 & 248 \\
\hline \multicolumn{7}{|l|}{ Unique increases in GMV for Dys 1} \\
\hline \multirow{2}{*}{$\begin{array}{l}\text { Dys } 1>\text { control masked incl. (Dys } \\
1>\text { Dys } 2 \& \text { Dys } 1>\text { Dys } 3 \text { ) }\end{array}$} & R putamen & 23 & -3 & -6 & 4.72 & 239 \\
\hline & $\begin{array}{l}\text { L cerebellum (crus } 1, \mathrm{VI}) \text {, } \\
\text { lingual gyrus }\end{array}$ & -14 & -81 & -19 & 4.70 & 399 \\
\hline Unique decreases in GMV for Dys 2 & & - & & & & \\
\hline Unique increases in GMV for Dys 2 & & - & & & & \\
\hline Unique decreases in GMV for Dys 3 & & - & & & & \\
\hline Unique increases in GMV for Dys 3 & & - & & & & \\
\hline \multicolumn{7}{|c|}{ Common decreases in GMV for Dys 1 and Dys 2} \\
\hline $\begin{array}{l}\text { Dys } 1 \& \text { Dys } 2<\text { control masked incl. } \\
\text { (Dys } 1<\text { con } \& \text { Dys } 2<\text { con \& Dys } \\
1<\text { Dys } 3 \& \text { Dys } 2<\text { Dys } 3 \text { ) }\end{array}$ & $\begin{array}{l}\mathrm{R} \text { anterior/middle } \\
\text { cingulate gyrus }\end{array}$ & 5 & 7 & 30 & 4.41 & 367 \\
\hline Common increases in GMV for Dys 1 & and Dys 2 & - & & & & \\
\hline Common decreases in GMV for Dys 1 & and Dys 2 & - & & & & \\
\hline \multicolumn{7}{|c|}{ Common increases in GMV for Dys 1 and Dys 3} \\
\hline $\begin{array}{l}\text { Dys } 1 \& \text { Dys } 3>\text { control masked incl. } \\
\text { (Dys } 1>\text { con \& Dys } 2>\text { con } \& \text { Dys } \\
1>\text { Dys } 2 \& \text { Dys } 3>\text { Dys } 2 \text { ) }\end{array}$ & $\begin{array}{l}\text { L cerebellum (VI, crus } 1), \\
\text { lingual gyrus }\end{array}$ & -21 & -66 & -19 & 4.18 & 864 \\
\hline \multicolumn{2}{|c|}{ Common decreases in GMV for Dys 2 and Dys 3} & - & & & & \\
\hline \multicolumn{2}{|c|}{ Common increases in GMV for Dys 2 and Dys 3} & - & & & & \\
\hline
\end{tabular}

and movements of the articulatory system. Poor quality articulatory representations lead to impaired sensitivity to the phonemic structure of language and to reduced phonological awareness. The second is related to decreased processing speed, which is reflected in difficulties with rapid naming.

Left somatosensory and right premotor cortices GMV reduction in the first subtype might suggest problems with articulatory feedback, which produces a severe phonological deficit. This in turn might cause greater reliance on silent articulatory processes (Wimmer et al. 2010) when dealing with decoding resulting in increased GMV in cerebellum and putamen. The role of the latter in reading, mainly silent articulation (Hernandez and Fiebach 2006) and phonology (Tettamanti et al. 2005) has been shown previously although it was not specifically linked with dyslexia.

Interestingly, one structure, the right anterior/middle cingulate gyrus showed a common decrease of GMV for both the first and second dyslexic subtype. This region is widely believed to play a role in cognitive control, helping to resolve conflict from distracting events by focusing attention towards task-relevant stimuli (Weissman et al. 2005). Several studies have suggested a role of anterior cingulate during anticipation (Murtha et al. 1996) and voluntary attentional orienting (Hopfinger et al. 2000; Weissman et al. 2002). It was also shown that activity in this region was correlated with the level of attention dedicated to learning events (Bryden et al. 2011). Both the first and the second dyslexic subtype, although at first glance seemingly different with regard to the behavioral profile, showed deficits in two different tasks requiring high amounts of attentional control-coherent dot motion and stream segregation. It was shown that performance in the formed is largely modulated by attention orienting (Liu et al. 2006), whereas the latter is regarded as a measure of attention shifting (Lallier et al. 2009). It seems possible that the reduced GMV in the right anterior cingulate might lead to poorer performance on these two different tasks involving attention focusing. In line, anterior cingulate was consistently revealed as having decreased GMV in attention deficit disorder (Amico et al. 2011; Seidman et al. 


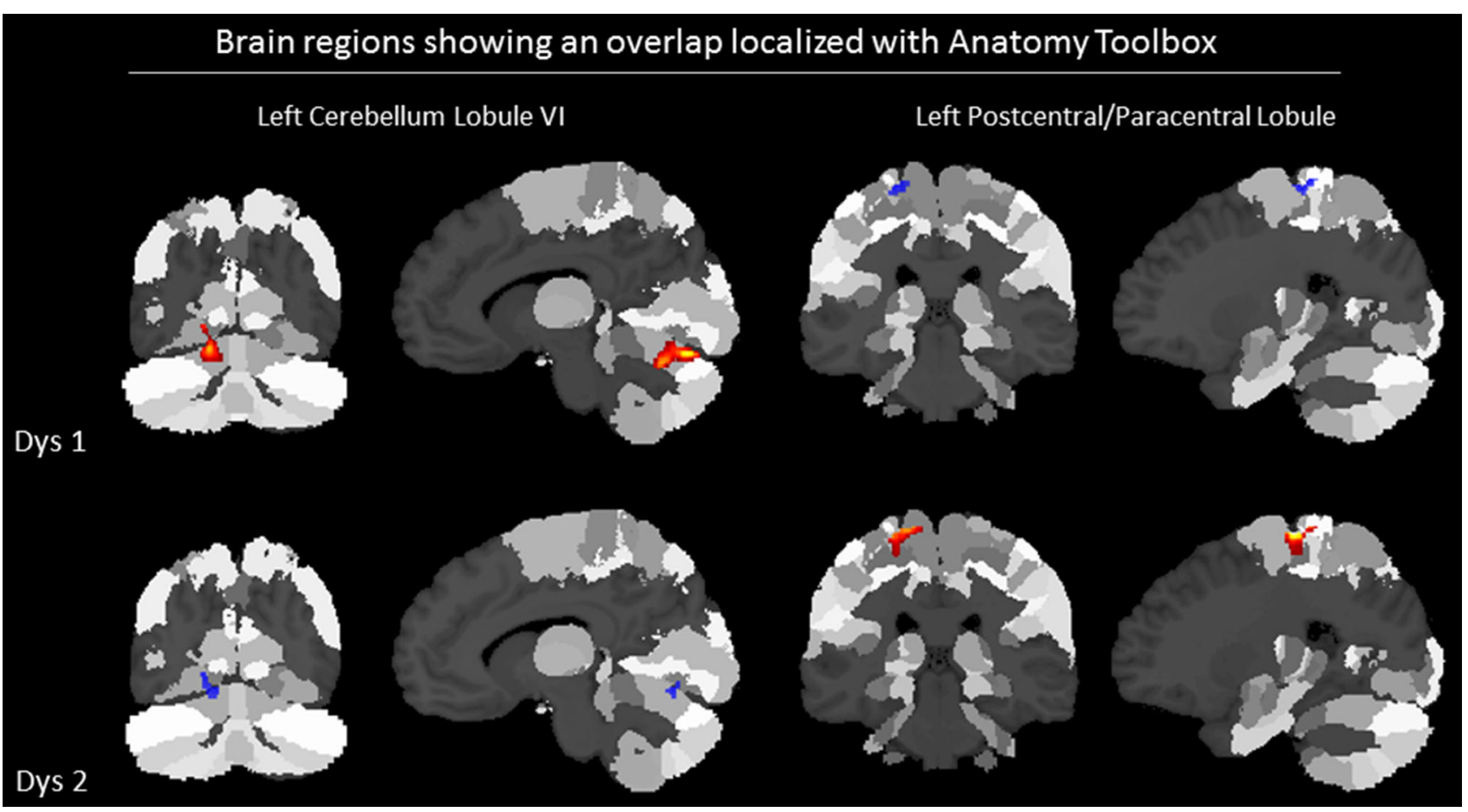

Fig. 3 Brain regions displaying an overlap between the two dyslexic subgroups localized with Anatomy Toolbox (in red decreased GMV; in blue increased GMV)

Table 5 Correlations between discriminating variables and standardized canonical discriminant functions

\begin{tabular}{lrrr}
\hline Discriminating variables & \multicolumn{2}{l}{ Function } \\
\cline { 2 - 4 } & 1 & 2 & \multicolumn{1}{l}{3} \\
\hline L parietal cortex & $0.617^{\mathrm{a}}$ & 0.219 & -0.117 \\
L cerebellum & $-0.497^{\mathrm{a}}$ & -0.149 & -0.031 \\
R superior frontal gyrus & $0.442^{\mathrm{a}}$ & 0.318 & -0.272 \\
R putamen & $-0.426^{\mathrm{a}}$ & 0.027 & -0.345 \\
R dorsal premotor cortex & $0.415^{\mathrm{a}}$ & -0.410 & 0.302 \\
R parietal cortex & -0.085 & $0.788^{\mathrm{a}}$ & 0.102 \\
L inferior frontal gyrus & 0.062 & -0.017 & $0.825^{\mathrm{a}}$ \\
\hline
\end{tabular}

${ }^{a}$ Largest absolute correlation between each variable and any discriminant function

2006). It remains, however, unclear why these two dyslexic subtypes are impaired either in coherent motion or SST and not in both. Most probably, the whole pattern of GMV changes and not only differences the right anterior cingulate influence the behavioral outcome.

The third subtype had a double deficit [described before by Wolf and Bowers (1999)], whereas it had preserved magnocellular-dorsal and attentional shifting skills. Compared to other groups it was characterized of lower GMV in the right parietal cortex, however, no unique effects were found for this subtype. The right parietal cortex contributed to the second discriminant function significantly correlated with both perceptual thresholds-magnocellular-dorsal and auditory attention shifting. The role of right inferior parietal cortex for attention was well documented (Behrmann et al. 2004). It is also known that visual input the right parietal cortex projects from the magnocellular layers of the lateral geniculate nucleus (Eden and Zeffiro 1998). We found that the lower the perceptual thresholds the lower the GMV in the right inferior parietal cortex, in agreement with previous studies showing significantly larger GMV in inferior parietal lobule in adults with ADHD (Seidman et al. 2011). Additionally the third subtype showed common with the first subtype increase of GMV in the left cerebellum cluster, possibly reflecting deficient phonological awareness skills.

On the basis of the GMV in the significant clusters described above using a discriminant analysis, $79 \%$ of cross-validated cases were correctly re-classified into four groups (controls versus three dyslexic subtypes).

In conclusion, our results are in line with the hypothesis that dyslexic subtypes can be characterized by specific patterns of GMV. We have dissociated three different groups of dyslexic behavior and identified brain areas with local GMV that differs from controls and between dyslexic groups. However, it seems that the relationship between brain structure and behavior is more complicated than anticipated, i.e., there is no clear, unique patterning of GMV differences. The obtained results form an intricate pattern of differences and not a plain 1:1 association 
between one subgroup and one region. Thus, based on a GMV difference in a specific brain area it is not possible to univocally predict the behavioral phenotype.

On the other hand, taking into account the complex aetiology of dyslexia it is not surprising that the array of GMV differences is also complex. Besides, having only four different cognitive tests, one cannot expect to fully describe the behavioral and neural phenotypes of dyslexia. Nevertheless, our study shows that it is important to look for potential subtyping of this disorder both on the behavioral and brain level. Further studies with a larger battery of cognitive tests and bigger sample size are needed to verify current findings. Lastly, it would be important to examine whether the revealed profiles (subtypes) are stable in development and whether they can be differentiated in younger children at the pre-reading stage.

Acknowledgments This study was supported by the Polish Ministry of Science grants: IP2010 015170, IP2011 020271 and by the grant of National Science Centre DEC-2011/03/D/HS6/05584. Stefan Heim was funded by the German Ministery for Education and Research (Bundesministerium für Bildung und Forschung, BMBF, grant 01GJ0804).

Open Access This article is distributed under the terms of the Creative Commons Attribution License which permits any use, distribution, and reproduction in any medium, provided the original author(s) and the source are credited.

\section{References}

Amico F, Stauber J, Koutsouleris N, Frodl T (2011) Anterior cingulate cortex gray matter abnormalities in adults with attention deficit hyperactivity disorder: a voxel-based morphometry study. Psychiatry Res 191:31-35

Ashburner J (2007) A fast diffeomorphic image registration algorithm. Neuroimage 38:95-113

Ashburner J, Friston KJ (2005) Unified segmentation. Neuroimage 26:839-851

Behrmann M, Geng JJ, Shomstein S (2004) Parietal cortex and attention. Curr Opin Neurobiol 14:212-217

Bogdanowicz M, Jaworowska A, Krasowicz-Kupis G, Matczak A, Pelc-Pękala O, Pietras I, Stańczak J, Szczerbiński M (2008) Diagnoza dysleksji u uczniów klasy III szkoły podstawowej. Pracownia Testów Psychologicznych, Warszawa

Bosse ML, Tainturier MJ, Valdois S (2007) Developmental dyslexia: the visual attention span deficit hypothesis. Cognition 104:198-230

Brambati SM, Termine C, Ruffino M, Stella G, Fazio F, Cappa SF, Perani D (2004) Regional reductions of gray matter volume in familial dyslexia. Neurology 63:742-745

Brett M, Anton J-C, Valabregue R, Poline J-B (2002) Region of interest analysis using an SPM toolbox (abstract). Presented at the 8th international conference on functional mapping of the human brain, Sendai, 2-6 June 2002

Brown WE, Eliez S, Menon V, Rumsey JM, White CD, Reiss AL (2001) Preliminary evidence of widespread morphological variations of the brain in dyslexia. Neurology 56:781-783

Bryden DW, Johnson EE, Tobia SC, Kashtelyan V, Roesch MR (2011) Attention for learning signals in anterior cingulate cortex. J Neurosci 31:18266-18274
Eckert MA, Leonard CM, Wilke M, Eckert M, Richards T, Richards A, Berninger V (2005) Anatomical signatures of dyslexia in children: unique information from manual and voxel based morphometry brain measures. Cortex 41:304-315

Eden GF, Zeffiro TA (1998) Neural systems affected in developmental dyslexia revealed by functional neuroimaging. Neuron 21:279-282

Hayasaka S, Phan KL, Liberzon I, Worsley KJ, Nichols TE (2004) Nonstationary cluster-size inference with random field and permutation methods. Neuroimage 22:676-687

Heim S, Grande M (2012) Fingerprints of developmental dyslexia. Trends Neurosci Educ 1:10-14

Heim S, Tschierse J, Amunts K, Wilms M, Vossel S, Willmes K, Grabowska A, Huber W (2008) Cognitive subtypes of dyslexia. Acta Neurobiol Exp 68:73-82

Heim S, Grande M, Pape-Neumann J, van Ermingen M, Meffert E, Grabowska A, Huber W, Amunts K (2010a) Interaction of phonological awareness and 'magnocellular' processing during normal and dyslexic reading: behavioural and fMRI investigations. Dyslexia 16:258-282

Heim S, Grande M, Meffert E, Eickhoff SB, Schreiber H, Kukolja J, Shah NJ, Huber W, Amunts K (2010b) Cognitive levels of performance account for hemispheric lateralisation effects in dyslexic and normally reading children. Neuroimage 53: 1346-1358

Heilman KM, Voeller K, Alexander AW (1996) Developmental dyslexia: a motor-articulatory feedback hypothesis. Ann Neurol 39:407-412

Hernandez AE, Fiebach CJ (2006) The brain bases of reading late learned words: evidence from functional MRI. Vis Cogn 13:1027-1043

Hoeft F, Meyler A, Hernandez A, Juel C, Taylor-Hill H, Martindale JL, McMillon G, Kolchugina G, Black JM, Faizi A, Deutsch GK, Siok WT, Reiss AL, Whitfield-Gabrieli S, Gabrieli JD (2007) Functional and morphometric brain dissociation between dyslexia and reading ability. Proc Natl Acad Sci USA 104:4234-4239

Hopfinger JB, Buonocore MH, Mangun GR (2000) The neural mechanisms of top-down attentional control. Nat Neurosci 3:284-291

Joly O, Ramus F, Pressnitzer D, Vanduffel W, Orban GA (2012) Interhemispheric differences in auditory processing revealed by fMRI in awake rhesus monkeys. Cereb Cortex 22:838-853

Kibby MY, Fancher JB, Markanen R, Hynd GW (2008) A quantitative magnetic resonance imaging analysis of the cerebellar deficit hypothesis of dyslexia. J Child Neurol 23:368-380

Kronbichler M, Wimmer H, Staffen W, Hutzler F, Mair A, Ladurner G (2008) Developmental dyslexia: gray matter abnormalities in the occipitotemporal cortex. Hum Brain Mapp 29:613-625

Lallier M, Thierry G, Tainturier MJ, Donnadieu S, Peyrin C, Billard C, Valdois S (2009) Auditory and visual stream segregation in children and adults: an assessment of the amodality assumption of the 'sluggish attentional shifting' theory of dyslexia. Brain Res 1302:132-147

Liu T, Fuller S, Carrasco M (2006) Attention alters the appearance of motion coherence. Psychon Bull Rev 13:1091-1096

Murtha S, Chertkow H, Beauregard M, Dixon R, Evans A (1996) Anticipation causes increased blood flow to the anterior cingulate cortex. Hum Brain Mapp 4:103-112

Nicolson RI, Fawcett AJ, Dean P (2001) Developmental dyslexia: the cerebellar deficit hypothesis. Trends Neurosci 24:508-511

Pernet C, Andersson J, Paulesu E, Demonet JF (2009) When all hypotheses are right: a multifocal account of dyslexia. Hum Brain Mapp 30:2278-2292

Ramus F, Ahissar M (2012) Developmental dyslexia: The difficulties of interpreting poor performance, and the importance of normal performance. Cogn Neuropsychol 
Ramus F, Rosen S, Dakin SC, Day BL, Castellote JM, White S, Frith U (2003) Theories of developmental dyslexia: insights from a multiple case study of dyslexic adults. Brain 126:841-865

Richardson FM, Price CJ (2009) Structural MRI studies of language function in the undamaged brain. Brain Struct Funct 213:511-523

Seidman LJ, Valera EM, Makris N, Monuteaux MC, Boriel DL, Kelkar K, Kennedy DN, Caviness VS, Bush G, Aleardi M, Faraone SV, Biederman J (2006) Dorsolateral prefrontal and anterior cingulate cortex volumetric abnormalities in adults with attention-deficit/hyperactivity disorder identified by magnetic resonance imaging. Biol Psychiatry 60:1071-1080

Seidman LJ, Biederman J, Liang L, Valera EM, Monuteaux MC, Brown A, Kaiser J, Spencer T, Faraone SV, Makris N (2011) Gray matter alterations in adults with attention-deficit/hyperactivity disorder identified by voxel based morphometry. Biol Psychiatry 69:857-866

Silani G, Frith U, Demonet JF, Fazio F, Perani D, Price C, Frith CD, Paulesu E (2005) Brain abnormalities underlying altered activation in dyslexia: a voxel based morphometry study. Brain 128:2453-2461

Steinbrink C, Vogt K, Kastrup A, Müller HP, Juengling FD, Kassubek J, Riecker A (2008) The contribution of white and gray matter differences to developmental dyslexia: insights from DTI and VBM at 3.0 T. Neuropsychologia 46:3170-3178

Talcott JB, Hansen PC, Assoku EL, Stein JF (2000) Visual motion sensitivity in dyslexia: evidence for temporal and energy integration deficits. Neuropsychologia 38:935-943

Tettamanti M, Moro A, Messa C, Moresco RM, Rizzo G, Carpinelli A, Matarrese M, Fazio F, Perani D (2005) Basal ganglia and language: phonology modulates dopaminergic release. NeuroReport 16:397-401

Turkeltaub PE, Gareau L, Flowers DL, Zeffiro TA, Eden GF (2003) Development of neural mechanisms for reading. Nat Neurosci 6:767-773

Uncapher MR, Rugg MD (2009) Selecting for memory? The influence of selective attention on the mnemonic binding of contextual information. J Neurosci 29:8270-8279

Vinckenbosch E, Robichon F, Eliez S (2005) Gray matter alteration in dyslexia: converging evidence from volumetric and voxel-byvoxel MRI analyses. Neuropsychologia 43:324-331

Weissman DH, Mangun GR, Woldorff MG (2002) A role for topdown attentional orienting during interference between global and local aspects of hierarchical stimuli. Neuroimage 17:1266-1276

Weissman DH, Gopalakrishnan A, Hazlett CJ, Woldorff MG (2005) Dorsal anterior cingulate cortex resolves conflict from distracting stimuli by boosting attention toward relevant events. Cereb Cortex 15:229-237

White S, Milne E, Rosen S, Hansen P, Swettenham J, Frith U, Ramus F (2006) The role of sensorimotor impairments in dyslexia: a multiple case study of dyslexic children. Dev Sci 9:237-255

Wilke M, Holland SK, Altaye M, Gaser C (2008) Template-O-Matic: a toolbox for creating customized pediatric templates. Neuroimage 41:903-913

Wimmer H, Schurz M, Sturm D, Richlan F, Klackl J, Kronbichler M, Ladurner G (2010) A dual-route perspective on poor reading in a regular orthography: an fMRI study. Cortex 46:1284-1298

Wolf M, Bowers P (1999) The "double-deficit hypothesis" for the developmental dyslexias. J Educ Psychol 91:1-24 